\title{
Atrioventricular Nodal Reentrant Tachycardia (AVNRT)
}

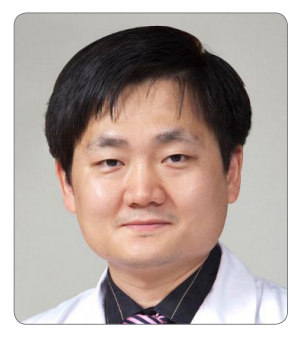

고점석

원광대학교 의과대학 내과학교실

Jumsuk Ko, MD, PhD

Department of Cardiology Wonkwang University of Medicine \& Hospital, Iksan, Republic of Korea

Received: November 11, 2016

Revision Received: November 18, 2016 Accepted: January 4, 2017

Correspondence: Jumsuk Ko, MD, PhD

Department of Cardiology Wonkwang University of Medicine \& Hospital, 895, Muwang-ro, Iksan-

si, Jeollabuk-do 54538, Republic of Korea

Tel: +82-63-859-2526 Fax: +82-63-852-8480

E-mail: nemor@daum.net

Copyright () 2017 The Official Journal of Korean Heart Rhythm Society Editorial Board \& MMK Co., Ltd.

\begin{abstract}
Atrioventricular nodal reentrant tachycardia is the most common type of supraventricular tachycardia. The initiation and maintenance of tachycardia is caused by the characteristic anatomic and electrophysiologic properties of the atrioverntricular node. Acute management for the termination of tachycardia includes pharmacologic and non-pharmacologic management. There are several options for preventing recurrence of tachycardia, and radiofrequency ablation for modulation of tachycardia circuit can be considered as a primary strategy. A thorough understanding of the unique electrophysiologic features is very essential for optimal management and best possible outcome in cases of invasive management.
\end{abstract}

Key Words: - Supraventricular Tachycardia -AVNRT

\begin{abstract}
서론
방실결절 회귀성 빈맥은 심실상 빈맥의 가장 흔한 원인을 차지하고 있다. 임상적으로는 좁은 QRS 빈맥의 소견을 보이며 갑작스런 두근거림을 호소하는 경우가 많다. 방실결절 회귀 빈맥의 병인은 방실결절의 특징적인 해부학적 전기생리학적 구조에 기인하는 것으로, 그동안 이루어진 많은 연구를 통해 병태생리 및 치료 전략이 어느 정도 정립된 상태이다. 본 논고에서는 2015년 개정된 $\mathrm{AHA} / \mathrm{ACC}$ 치료지침을 바탕으로 하여 이에 대해 간략히 정리하고자 한다.
\end{abstract}

\section{방실결절의 해부학적인 특징과 방실결절 회귀 빈 맥의 발생기전}

방실결절은 심방중격에 있는 Koch 삼각형에 위치한다. Koch 삼각형은 삼첨판의 중격판막첨, 관상정맥동, Tordaro 건을 경계로 하여 심방중격의 심내막측에 위치하는 가상의 구조물이다. 조직학적으로는 크게 두 가지의 서로 다른 세포로 구성되어 있는데, 방실결절 세포들의 조밀한 집합체인 compact zone과 전이세포들로 구성되어 compact zone을 둘러싸고 있는 transitional zone으로 나뉜다.

방실결절은 심방조직과의 연결에 있어 크게 세 방향으로 연장된 조직을 가질 수 있는데, 급속전도로는 전도속도가 
빠르지만 불응기가 긴 특성을 가지며 Tordaro 건의 상방에서 transitional zone을 가로질러 방실결절과 연결된다. 완속전도로는 전도속도는 느리지만 불응기가 짧은 특성을 가지며 방실결절의 우하방이나 좌하방으로 연장된 조직이다. 이와 같이 방실결절과 심방조직이 상이한 전기생리학적인 특성을 가진 조직들을 통해 연결되므로 각각의 전도로 사이에서 회귀(reentry)가 발생할 수 있으며 이는 방실결절 회귀성 빈맥이 발생하는 해부학적인 기질을 제공한다. 회귀가 일어나는 회로는 상행전도로-하행전도로로 어떤 전도로가 참여하는가에 따라 급속전도로-완속전도로, 완속전도로급속전도로, 완속전도로-완속전도로와 같이 다르게 성립할 수 있으며, 이에 따라 심전도 및 전기생리학적으로 다른 특성을 보이게 된다.

\section{방실결절 회귀성 빈맥의 임상적인 특징}

\section{심전도 소견}

전형적인 방실결결 회귀성 빈맥은 좁은 QRS파 빈맥의 소견을 보이나 편위전도가 동반된 경우 넓은 $\mathrm{QRS}$ 파 빈맥의 소견을 보일 수 있다. 빈맥 지속 중 일부에서는 ST분절의 하강이나 RR간격의 변이가 관찰되는 경우도 있다.

빈맥 중 역행성 $\mathrm{P}$ 파의 위치는 방실결절 회귀성 빈맥의 유형에 따라 다르며 전형적인 방실결절 회귀성 빈맥( 완속전도로-급속전도로)의 경우 $\mathrm{P}$ 파는 QRS파에 가려져서 보이지 않거나 QRS파 말단 부위를 변형시키는 경우가 일반적이다. 반면 비전형적인 방실결절 회귀성 빈맥( 급속전도로-완속전도로)의 경우 역행성 $\mathrm{P}$ 파가 $\mathrm{QRS}$ 앞에서 관찰되는 긴 $\mathrm{RP}$ 간격 $\left(\mathrm{RP}^{\prime} / \mathrm{P}^{\prime} \mathrm{R}>0.75\right)$ 빈맥을 관찰할 수 있다. 역행성 P파의 전기축은 하부유도인 II, III, $\mathrm{aVF}$ 에서는 음성이고 $\mathrm{V}_{1}$ 에서는 양성이며 드물게 방실해리가 관찰될 수 도 있는데, 이는 빈맥의 회로에 심실이 포함되어 있지 않기 때문이다. 빈맥이 시작하는 지점에서 전형적인 방실결절 회귀성 빈맥의 경우 심방조기박동 이후 PR간격의 연장을 관찰할 수도 있다.

\section{임상 증상}

방실결절 회귀성 빈맥은 대부분의 경우 발작성 심실상
빈맥의 형태로 나타난다. 두근거리는 증상이 갑자기 발생하면 증상의 종료도 갑작스럽게 일어난다. 호흡곤란이나 흥통을 호소할 수 있으며 현기증을 동반하거나 실신에 이르는 경우도 있을 수 있다. 목에서 쿵쾅거리는 느낌을 호소하는 경우도 있는데, 이는 삼첨판 및 승모판이 폐쇄된 상태에서 심방과 심실이 동시에 수축하므로 발생한다.

\section{방실결절 회귀성 빈맥의 치료}

\section{방실결절 회귀성 빈맥의 급성기 치료 (Figure 1)}

방실결절 회귀성 빈맥의 유지에 있어 방실결절이 회귀 회로 내에 위치하므로 방실결절의 전도속도를 지연시키거나 전도를 차단시키는 처치로써 빈맥을 종료시킬 수 있다. 비약물적인 요법으로는 미주신경을 항진시키는 발살바 수기 (Valsalva maneuver)나 경정맥동 마사지(carotid sinus massage)가 있고, 약물요법으로는 adenosine이 우선적인 치료약제이며(class I) verapamil, diltiazem 및 베타차단제를 정주하여 빈맥을 종료시킬 수도 있다(class $\Pi \mathrm{Ia}$ ). 저혈압 또는 쇼크가 동반되는 경우나 약제에 의해 빈맥이 종료되지 않는

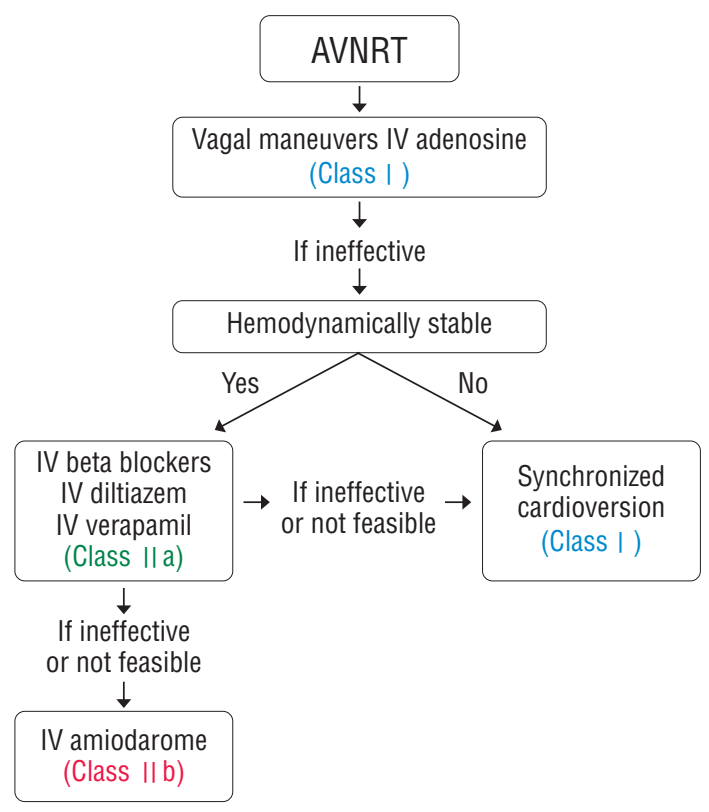

Figure 1. Acute treatment of AVNRT

For rhythms that break or recur spontaneously, synchronized cardioversion is not appropriate.

AVNRT, atrioventricular nodal reentrant tachycardia; IV, intravenous 
경우 직류 동율동 전환을 우선적으로 고려해야 한다(class I). ${ }^{2}$

\section{심장전기 생리검사 및 전극도자절제술 (Figure 2)}

\section{침습적인 치료의 적응증}

빈맥의 재발을 막기 위해 침습적인 방법을 통해 해부학적인 기질을 제거하는 것을 일차적인 치료로 고려할 수 있다(class I). 대개는 전극도자절제술 이후에 추가적인 약물치료가 필요하지 않는데, 이는 방실전도 차단과 같은 주요 합병증의 발생 가능성이 $1 \%$ 미만으로 매우 낮기 때문이다. ${ }^{3}$ 침습적인 시술 여부는 다양한 요소를 고려해야 하는데 빈맥의 발생 빈도 및 발작 시의 증상이 얼마나 심한지, 약물치료를 선택할 경우 약제에 대한 반응이 양호한지도 평가해야 한다. 환자의 나이 및 동반질환에 따라 지속적인 약물치료를 원하지 않는 경우에도 침습적인 치료를 우선적으로 고려할 수 있다. 환자가 전극도자절제술의 대상이 되지 않거나 약물치료를 원하는 경우 verapamil이나 베타차단제를 투여할 수 있다. 빈맥의 재발을 막기 위해 flecainide나 propafenone과 같은 항부정맥제를 사용하는데 치료 없이 경과를 관찰하는 것은
우선적으로 추천되는 방법은 아니다(class IIa).

\section{심장전기 생리검사}

심장전기 생리검사에서 우선적으로 확인해야 할 것은 불연속적인 방실 전도의 존재 여부이다. 심방조기자극의 간격을 점진적으로 짧게 하면서 $\mathrm{AH}$ 간격을 측정하였을 때 같이 점진적으로 증가하는 소견을 볼 수 있으며, 이는 방실결절이 가지고 있는 고유한 전기생리학적 특징이다. 그런데 이중 방실전도를 가지고 있는 경우 특정 시점에서 완속전도로를 통한 방실전도가 이루어지면서 갑자기 $\mathrm{AH}$ 간격이 증가하는 소견( $\mathrm{AH}$ 도약)을 관찰할 수 있다. 일반적으로 심방조기자극의 간격을 $10 \mathrm{~ms}$ 감소시켰을 때 $\mathrm{AH}$ 간격이 $50 \mathrm{~ms}$ 이상 증가하는 경우 $\mathrm{AH}$ 간격의 도약이 있다고 간주할 수 있다. AH도약은 한 번만 있는 경우도 있으나 두 번 이상의 도약이 있는 경우도 드물지는 않으며, 이는 복수의 다른 기능을 가지는 전도로가 있음을 시사한다. ${ }^{4}$ 이러한 $\mathrm{AH}$ 도약은 방실결절 회귀성 빈맥에 있어 전형적으로 관찰되는 소견이나 어떤 경우에는 $\mathrm{AH}$ 도약 없이 급속전도로의 역행전도를 통한 echo및 빈맥이 발생하는 경우도 있으며, $\mathrm{AH}$

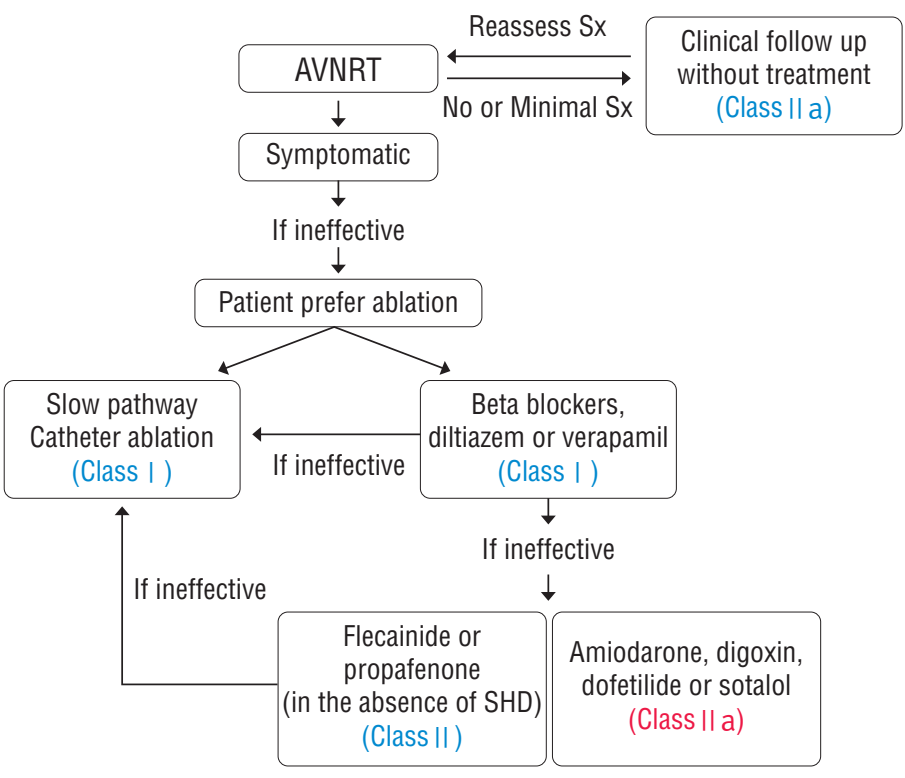

Figure 2. Ongoing management of AVNRT

AVNRT, atrioventricular nodal reentrant tachycardia; SHD, structural heart disease (including ischemic heart disease); Sx, symptom 
도약이 관찰되었으나 빈맥의 기전은 방실결절 회귀가 아닌 경우도 있을 수 있으므로 $\mathrm{AH}$ 도약의 존재 유무를 방실결절 회귀성 빈맥과 단정적으로 연관 짓지 않아야 할 것이다.

빈맥을 유도하기 위해서는 일반적으로 심방조기자극을 이용하는 것이 점진적으로 조기자극 간격을 줄여가면서 특정 $\mathrm{AH}$ 간격에 도달했을 때 급속전도로가 불응기를 벗어나면서 역행전도가 이루어지고 회귀성 빈맥이 유발되는 것을 확인할 수 있다. 회귀가 발생하는 $\mathrm{AH}$ 간격은 고정적인 것이 아니며 자율신경계 흥분 정도에 따라 다를 수 있으므로 안정상태에서 빈맥이 유발되지 않는 경우 isoproterenol 정주를 병행할 수 있다. 또한 앞서 언급한 바와 같이 다양한 회귀 회로가 존재할 수 있으며 심방자극의 위치에 따라 다른 반응을 보일 수 있으므로 우심방 부위의 자극으로 빈맥이 유발되지 않는 경우 관상정맥동의 자극도 같이 시행하는 것이 바람직하다.

빈맥이 유발되고 나면 심방빈맥이나 방실 회귀성 빈맥과의 감별이 필요하다. 다양한 방법이 있으나 몇 가지 기본적인 방법을 언급하자면 다음과 같다.

\section{1) 빈맥 주기의 변동성}

빈맥이 진행되는 도중에 빈맥 주기에 변동이 있는 것을 드물지 않게 관찰할 수 있으며 전형적인 방실결절 회귀성 빈맥의 경우 이는 주로 완속전도로를 통한 하행전도속도의 변화에 따라 발생하며 급속전도로를 통한 상행전도속도에 변화가 있는 경우는 드물다. 따라서 VV간격의 변화가 AA 간격의 변화에 선행하며 반대의 경우에는 방실 회귀성 빈맥의 가능성이 보다 높다.

2) 편위전도 발생 시 빈맥 주기의 변화 여부

방실결절 회귀성 빈맥에서는 빈맥 중 편위전도가 발생하였을 때 빈맥주기에 의미 있는 변화가 없으며 변화가 있는 경우 편측의 방실우회로를 통한 방실 회귀성 빈맥의 가능성을 고려해야 한다.

\section{3) 심실동조자극(ventricular entrainment pacing)}

빈맥 진행 중에 빈맥 주기보다 10-30 ms 정도 빠르게 심실동조자극을 시행하였을 때 심실자극 종료 후 다음 심실 신호까지의 간격과 빈맥 주기에 $115 \mathrm{~ms}$ 이상 차이가 있는
경우 방실결절 회귀성 빈맥을 시사한다.

\section{전극도자절제술}

방실결절 회귀성 빈맥의 치료에 있어 전극도자절제술의 목표는 빈맥 회로를 구성하는 완속전도로의 제거 또는 변조를 통해 빈맥이 재발하지 않도록 하는 것이다. 전극도자절제술을 시행할 때 가장 중요한 것은 정상 전도로를 손상시켜 방실 전도 차단의 합병증이 발생하는 것을 피하는 것이다. 이를 위해서는 몇 가지 기본적인 원칙이 있다. 첫 번째는 빈맥의 유도를 위해 isoproterenol을 사용하였을 때는 가급적 isoproterenol을 중단한 상태에서 전극도자절제술을 시행하는 것이 좋다. 약제에 의해 심실의 수축이 격렬한 상황에서 에너지를 전달하는 경우 전극도자의 위치가 불안정하여 목표지점 이외에 손상을 줄 가능성이 있다. 두 번째는 빈맥이 진행하는 상황에서 전극도자절제술을 시행하는 것은 피하는 것이 좋다. 에너지 전달 중 빈맥이 종료되는 경우 종료 시점에 강한 심근수축이 발생하여 급작스럽게 전극도자의 위치가 변화할 수 있기 때문이다. 세 번째는 에너지를 전달하는 중에 항상 방실전도 상태를 확인해야 한다. 목표로 하는 완속전도로에 에너지를 전달하는 경우 접합부 율동이 자주 발생하는데 이때는 심방자극을 통해 방실전도를 확인하거나 접합부 율동 중에 역행전도가 정상적으로 이루어지는지를 반드시 확인해야 한다. 마지막으로 완속전도로를 완전히 차단하기 위해 방실결절이 손상될 수 있는 위험을 감수하지 않는 것이 바람직하다. 완속전도로를 통한 하행전도가 남아있다고 하더라도 전도속도나 불응기의 변화를 통해 충분히 변조되었다고 생각되는 경우 시술을 중단하는 것이 안전하다. $\mathrm{AH}$ 도약이 남아있고 echo파가 관찰되는 경우에도 완속전도로의 불응기에 충분히 변화가 오거나 $1: 1$ 전도가 소실된 경우 빈맥이 재발할 가능성이 높지 않기 때문이다.

완속전도로를 목표로 하여 에너지를 전달하기 위해서는 삼첨판륜와 경정맥동 개구부의 해부학적인 위치관계를 참조하여 전극도자를 위치시키고 에너지를 가하면서 점진적으로 위치를 변경하는 방법(해부학적인 접근법)과 전극도자에서 완속전도로 전위(slow pathway potential)가 기록되는 지점을 찾는 방법(전기해부학적인 접근법)이 있다. 후자의 경우 완속전도로 전위는 심방 신호 바로 뒤에서 기록되며 방실결절이 우하방으로 연장되는 경우 일반적으로 
Koch 삼각형과 경정맥동 개구부 사이의 전중격 부위에서 기록된다. 그러나 전술한 바와 같이 완속전도로의 위치에는 다양한 변이가 있을 수 있으며 경정맥동이나 심방중경의 좌심방측에서 시술 부위를 찾아야 하는 경우도 있다.

\section{결론}

방실결절 회귀성 빈맥은 발작성 심실상 빈맥의 흔한 원인이다. 주의 깊은 병력청취와 심전도 해석을 통해 정확한 진단을 위해 노력해야 하며 치료 전략으로써 전극도 자절제술을 선택할 경우 정확한 해부학적 및 전기생리학적인 이해를 통해 접근하는 경우 대부분 좋은 결과를 얻을 수 있을 것으로 생각된다.

\section{References}

1) Hucker WJ, McCain ML, Laughner JI, Iaizzo PA, Efimov IR. Connexin 43 expression delineates two discrete pathways in the atrioventricular junction. Anat Rec (Hoboken). 2008;291:204-215.

2) Page RL, Joglar JA, Caldwell MA, Calkins H, Conti JB, Deal BJ, Estes NA, 3rd, Field ME, Goldberger ZD, Hammill SC, Indik JH, Lindsay BD, Olshansky B, Russo AM, Shen WK, Tracy CM, Al-Khatib SM. 2015 ACC/AHA/HRS guideline for the management of adult patients with supraventricular tachycardia: a report of the American College of Cardiology/American Heart Association task force on clinical practice guidelines and the Heart Rhythm Society. Circulation. 2016;133:e506-e574.

3) Hindricks G. Incidence of complete atrioventricular block following attempted radiofrequency catheter modification of the atrioventricular node in 880 patients. Results of the Multicenter European Radiofrequency Survey (MERFS) The Working Group on Arrhythmias of the European Society of Cardiology. Eur Heart J. 1996;17:82-88.

4) Kuo CT, Luqman N, Lin KH, Cheng NJ, Hsu TS, Lee YS. Atrioventricular nodal reentry tachycardia withmultiple AH jumps: Electrophysiological characteristics and radiofrequency ablation. Pacing Clin Electrophysiol. 2003;26:1849-1855. 